\title{
Viabilidade da incorporação do mel de abelha em sachê na alimentação escolar de uma instituição de Ensino de São Domingos-PB.
}

\section{Bee Honey incorporation of viability in sachet in school feeding an institution of Education of São Domingos-PB.}

\author{
Walnara Arnaud Moura Formiga ${ }^{1}$, Antônio Vitor Machado ${ }^{2}$, Patrício Borges Maracajá3 ${ }^{3}$ Bárbara Bruna Maniçoba Pereira ${ }^{4}$, \\ Debora Cristina Coelho
}

Resumo- A alimentação escolar deve oferecer alimentos naturais e de boa qualidade para garantir o aprendizado e melhorar a qualidade de vida dos alunos na escola. No Brasil o Programa Nacional de Alimentação Escolar-PNAE precisa ter em sua execução alimentos naturais e com muitos benefícios para seus comensais, dentre os muitos alimentos com a referida qualidade, encontramos o mel de abelha, um alimento natural, que se constitui de uma solução supersaturada de glicose e frutose, além de ser rico em micronutrientes essenciais ao organismo humano, por sua constituição, o referido alimento fornece aos indivíduos que o consomem propriedades antibacterianas, anti-inflamatórias, energéticas, antioxidantes, entre outras. Neste contexto este trabalho objetivou avaliar o nível de aceitabilidade do mel de abelha embalado em sachês introduzido na alimentação escolar do município de São Domingos-PB. O estudo teve um caráter descritivo, exploratório e quantitativo. A pesquisa foi realizada numa escola de ensino fundamental na zona urbana do município de São Domingos-PB e teve uma população de 180 alunos matriculados na referida escola. O plano de amostragem para os alunos foi estabelecido de acordo com o proposto por Barbetta (2001), com a seleção de amostras aleatórias simples entre os mesmos, sendo o número de alunos calculado com um erro amostral tolerável de 4\%. Assim, o número de alunos foi igual a 60 crianças com idade variando entre 9 e 13 anos, infligiu-se questionários simples antes e após a introdução do mel na referida escola e as informações foram analisadas utilizando a estatística descritiva, empregando-se o programa estatístico IBM SPSS Statistics, versão 21 de 2012. Analisando os resultados percebeu-se que o mel de abelha em sachê apresentou uma excelente aceitabilidade na merenda escolar sendo viável a sua utilização permanente nos cardápios do Programa Nacional de Alimentação Escolar.

Palavras chave: alimentação, escola, mel de abelha.

\begin{abstract}
School feeding should offer natural and good quality food to ensure learning and improve the quality of life of students in school. In Brazil the National Program for School-PNAE Food need to have in its execution natural foods and with many benefits for their guests, among many foods with this status, we found the honey, a natural food, which consists of a solution supersaturated glucose and fructose, and is rich in essential micronutrients for human beings, by its constitution that food provides to individuals who consume antibacterial, anti-inflammatory, energy, antioxidants, among others. This article aims to assess the level of acceptability of honey packed in sachets inserted in the school feeding of São Domingos-PB. The study was a descriptive, exploratory and quantitative. The survey was conducted in a primary school in the urban area of the municipality of Santo Domingo-PB and had a population of 180 students enrolled in the school. The sampling plan for students was established according to the proposed by Barbetta (2001) with simple random sample selection between them, the number of students calculated a tolerable sampling error of 4\%. Thus, the number of students was equal to 60 children aged between 9 and 13 years, inflicted it simple questionnaires before and after the introduction of honey in this school and the data were analyzed using descriptive statistics, using the program statistical IBM SPSS, version 21 2012.Analisando the results it was observed that the honey sachet showed good acceptability in school meals being viable its continued use in the menus of the National School Feeding Programme
\end{abstract}

Keywords: food, school, honey.

\footnotetext{
*Autor para correspondência

Recebido para publicação em 07/01/2015; aprovado em 26/05/2015

${ }^{1}$ Mestre em Sistemas Agroindustriais, PPGSA-UFCG, Pombal-PB. E-mail: walnara@ hotmail.com

${ }^{2}$ Professora adjunto UFERSA E-mail: machadoav@ufersa.edu.br

${ }_{3}^{3}$ Professor adjunto CCTA/UATA/UFCG . E-mail:patriciomaracaja@ufcg.edu.br

${ }^{4}$ Mestre em Sistemas Agroindustriais, Universidade Federal de Campina Grande, Pombal; E-mail: barbara.bmp@hotmail.com

${ }^{5}$ Aluna de pós-graduação do curso de Sistemas Agroindustriais da Universidade Federal de Campina Grande.
} 


\section{INTRODUÇÃO}

A alimentação desempenha um papel primordial durante todo o ciclo de vida dos indivíduos. Entre as distintas fases da vida pode-se destacar, como exemplo, a idade escolar (de 6 a 13 anos), que se caracteriza por um período em que a criança apresenta um metabolismo muito mais intenso quando comparado ao do adulto, necessitando de uma alimentação adequada para seu desenvolvimento e aprendizagem (PHILIPPI, 2000).

A alimentação escolar precisa conter alimentos naturais e de boa qualidade, pois a criança nessa fase da vida passa a ser mais independente, decidindo, por si mesma, seus gostos, preferências e aversões, apresentando senso crítico e esses fatores vão refletir-se, claramente nos hábitos gerais e alimentares da criança (ACCIOLY et. al, 2012).

Para garantir o aprendizado e melhorar a qualidade de vida dos alunos na escola o Brasil criou um programa conhecido pelo nome de Merenda Escolar, o Programa Nacional de Alimentação Escolar-PNAE, que se baseia na deslocação de investimentos financeiros do Governo Federal, em caráter de aperfeiçoamento, aos estados, Distrito Federal e municípios, para a aquisição alimentos direcionados à alimentação escolar, seu intuito é satisfazer às exigências nutricionais dos estudantes enquanto a permanência em sala de aula, favorecendo o desenvolvimento, crescimento, aprendizagem, rendimento escolar e formação de hábitos alimentares saudáveis.

O PNAE é conhecido mundialmente como um caso de sucesso de Programa de Alimentação Escolar Sustentável e que precisa ter em sua execução alimentos naturais e com muitos benefícios para seus comensais, dentre os muitos alimentos com a referida qualidade, encontramos o mel de abelha, um alimento natural, que se constitui de uma solução supersaturada de glicose e frutose, além de ser rico em micronutrientes essenciais ao organismo humano, por sua constituição o referido alimento fornece aos indivíduos que o consomem propriedades antibacterianas, anti-inflamatórias, energéticas, antioxidantes, entre outras.

Observando-se a potencialidade de benefícios que esse alimento pode proporcionar, especialmente para a saúde dos escolares, o presente trabalho teve como principal objetivo a avaliação do nível de aceitabilidade do mel de abelha embalado em sachês introduzido na alimentação escolar do município de São Domingos-PB.

\section{MATERIAL E MÉTODOS}

O estudo teve um caráter descritivo, uma vez que sua valorização foi baseada na premissa de que as práticas podem ser melhoradas através de descrição e análise de observações objetivas e diretas. Foi também do tipo exploratória, pois sua finalidade propôs mostrar a possibilidade de um provável acontecimento futuro. Segundo Gil (2002) pode-se dizer que esse tipo de pesquisa tem como objetivo principal o aprimoramento de ideias ou a descoberta de intuições.

O presente trabalho possuiu também uma abordagem quantitativa, pois se utilizou medidas numéricas para testar as hipóteses e também se examinou aspectos mais profundos e subjetivos do tema em estudo, empregando procedimentos interpretativos com representação verbal dos dados coletados por meio de perguntas em questões abertas de caráter qualitativo (GUNTHER, 2006).
A pesquisa foi realizada numa escola de ensino fundamental na zona urbana do município de São DomingosPB que de acordo com o Serviço Geológico do Brasil CPRM (2005) possui esta localizado na região Oeste do Estado da Paraíba, Ocupa uma área de 227,2 quilômetros quadrados, fazendo parte do semiárido brasileiro. O município foi selecionado para a realização do trabalho por nunca ter sido ofertado o mel de abelha na alimentação escolar e por apresentar uma área propícia ao desenvolvimento da apicultura.

A População da pesquisa foi composta pelos 180 alunos matriculados na Escola Municipal de Ensino Fundamental Maria Marques de Assis I no município de São Domingos-PB.

O plano de amostragem para os alunos foi estabelecido de acordo com o proposto por Barbetta(2001) com seleção de amostra aleatória simples entre os mesmos, sendo o número de alunos calculado com um erro amostral tolerável de 4\%. Assim, o número de alunos foi igual a 60 crianças com idade variando entre 9 e 13 anos, o que representa $33,33 \%$ do total de alunos matriculados na unidade de ensino selecionada, sendo dividida em dois grupos de 30 alunos, $\mathrm{O}$ grupo 1 composto por alunos do turno manhã e um grupo 2 composto por alunos do turno tarde.

Infligiu-se no mês de setembro de 2013, antes do mel ser ofertado na escola, um questionário semiestruturado (Anexo I) à amostra de alunos da instituição em estudo com perguntas simples e objetivas, no intuito de se obter um perfil dos estudantes relacionado ao seu contato com o mel fora da escola, bem como saber a intenção dos mesmos em aceitar receber o mel de abelha na alimentação escolar.

Após esse momento, o mel de abelha em sachê foi oferecido no cardápio do mês de outubro de 2013, durante esse período cada aluno da escola Maria Marques de Assis recebeu como sobremesa para o cachorro-quente um sachê com $10 \mathrm{~g}$ de mel de abelha, seguindo as proporções estabelecidas por Pinheiro et. al, (2005).

Depois do mel de abelha em sachê ter sido ofertado na Alimentação Escolar da Escola Maria Marques em São Domingos-PB foi aplicado um novo questionário ( ANEXO II) onde foram realizadas 2 perguntas simples e fechadas e 2 perguntas utilizando a escala Hedônica facial de cinco pontos estabelecida pelo FNDE para teste de aceitabilidade no intuito de detectar como foi a tolerância dos alunos ao mel de abelha como alimento na escola.

Figura 01: Escala hedônica facial de cinco pontos

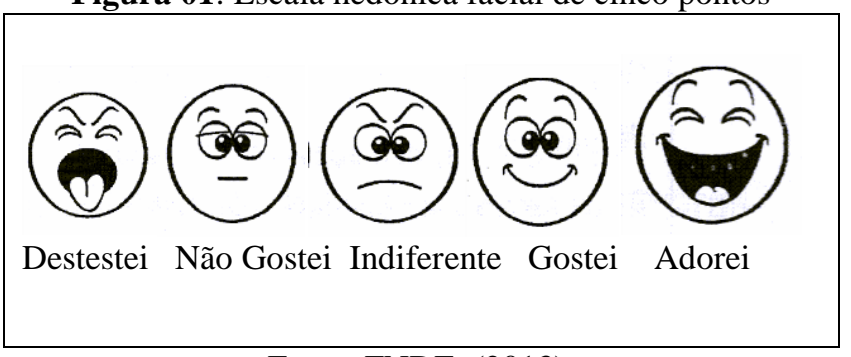

Fonte: FNDE, (2013).

As informações foram analisadas utilizando a estatística descritiva, empregando-se o programa estatístico IBM SPSS Statistics, versão 21 de 2012. 


\section{RESULTADOS E DISCUSSÃO}

Resultados da entrevista com alunos dos grupos $1 \mathrm{e}$ 2 antes da introdução do mel na merenda escolar:

Figura 02: Demonstração do consumo de mel pelos alunos do Grupo 1 em comparação aos do Grupo 2.
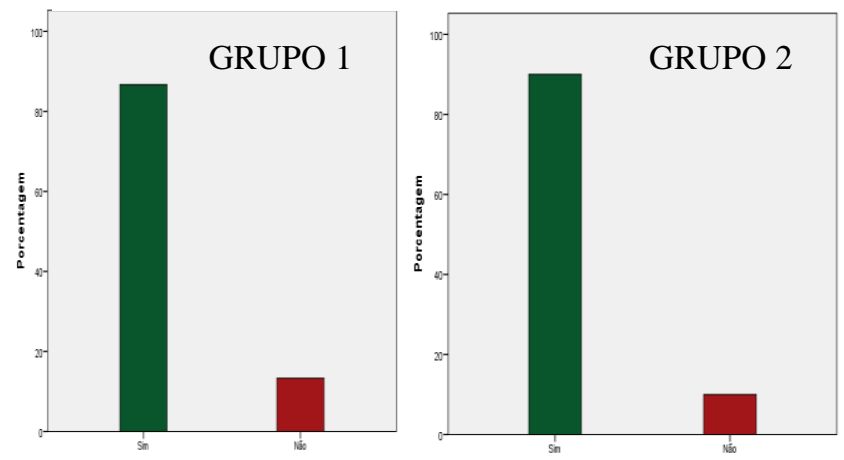

Ao serem perguntado se já haviam consumido o mel de abelha alguma vez na vida os dois grupos de alunos apresentaram um percentual semelhante nas respostas: no Grupo $190 \%$ dos entrevistados já tinham experimentado o alimento, enquanto apenas $10 \%$ destes nunca haviam ingerido o mel de abelha, no Grupo 2 86,7\% dos alunos haviam consumido o mel de abelha enquanto que $13,3 \%$ dos mesmos jamais provaram o referido alimento.

Os resultados acima mostram que o mel de abelha é um alimento comum e confirmam o que diz Silva (2006), que o mel é considerado o produto apícola mais fácil de ser explorado, sendo também o mais conhecido.

Tabela 01: Distribuição da amostra de alunos do Grupo1 e 2 que provaram o mel de abelha relacionada a terem gostado do sabor desse alimento

\begin{tabular}{lccc}
\hline Gostaram do sabor do mel & Grupo 1 & Grupo 2 & $\%$ \\
\hline Sim & 27 & 26 & 100 \\
Não & 0 & 0 & 0 \\
\hline Total & 27 & 26 & 100 \\
\hline
\end{tabular}

Tabela 02: Distribuição da amostra de alunos do Grupo1 e 2 que provaram o mel de abelha relacionada ao desejo de implantar esse alimento na merenda.

\begin{tabular}{lccc}
\hline Querem mel na merenda & Grupo 1 & Grupo 2 & $\%$ \\
\hline Sim & 27 & 26 & 100 \\
Não & 0 & 0 & 0 \\
\hline Total & 27 & 26 & 100 \\
\hline
\end{tabular}

Tabela 03: Distribuição da amostra de alunos do Grupo1 e 2 que nunca provaram o mel de abelha relacionada à vontade dos mesmos de experimentarem.

\begin{tabular}{lccc}
\hline Desejam experimentar mel & Grupo 1 & Grupo 2 & $\%$ \\
\hline Sim & 0 & 0 & 0 \\
Não & 3 & 4 & 100 \\
\hline Total & 3 & 4 & 100 \\
\hline
\end{tabular}

Observando as tabelas acima, percebe-se na tabela 01 que $100 \%$ dos alunos dos dois grupos que já ingeriram o mel de abelha gostaram de seu sabor e na tabela 02 que esse mesmo percentual de alunos em ambos os grupos anseiam a introdução do mel de abelha na merenda escolar, demonstrando que é um alimento de fácil aceitação, porém analisando a tabela 03 identifica-se que os alunos que nunca consumiram mel de abelha nos dois grupos também não possuem a intenção de experimentar, ratificando a afirmação de que as crianças são naturalmente predispostas a rejeitarem um alimento novo (neofobia) em seu hábito alimentar (VITOLO, 2008).

Tabela 04 Distribuição da amostra dos alunos ( grupos 1 e 2) que durante os anos de estudo nunca receberam o mel de abelha como alimento na alimentação escolar.

\begin{tabular}{lcc}
\hline Receberam mel na merenda & $\mathrm{N}^{\circ}$ de alunos & $\%$ \\
\hline Sim & 0 & 100 \\
Não & 60 & 0 \\
\hline Total & 60 & $100 \%$ \\
\hline
\end{tabular}

A tabela 04 demonstra a informação de que não existia mel de abelha no cardápio escolar de São DomingosPB antes do desenvolvimento deste trabalho, pois apesar da pesquisa ter sido realizada em um estabelecimento de ensino dos cinco existentes, os cardápios são padronizados e oferecidos igualmente em todas as escolas.

Do questionário aplicado a amostra de alunos (Grupo 1 e 2) após a oferta do mel de abelha em sache na merenda escolar.

Figura 03: Opinião dos alunos (grupos 1 e2) sobre a oferta do mel de abelha na merenda

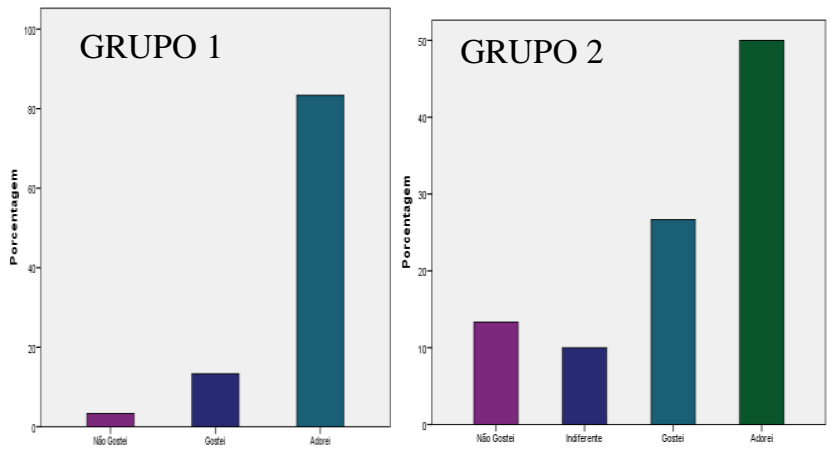

Percebe-se pela figura acima, que o gráfico que representa a aceitabilidade do GRUPO1 apresentou um melhor perfil de satisfação ao receber o mel na alimentação escolar, tendo $83,3 \%$ da amostra respondido que adorou a presença do mel na merenda, $13,3 \%$ disseram que gostaram dessa oferta e apenas 3,3\% não gostou do mel, representando um percentual de aceitabilidade para esse alimento de 96,6\%, indicando que por esse grupo o referido alimento pode ser introduzido na merenda da escola em estudo, pois o índice mínimo de aceitação para alimentos estabelecidos pelo FNDE é de no mínimo $85 \%$.

Segundo Magalhães (2005), a aceitação de um alimento pelo aluno é o principal fator que determina a qualidade do serviço prestado pelas escolas, no tocante ao fornecimento da merenda escolar. Segundo as normas do PNAE, as instituições de ensino deverão aplicar teste de aceitabilidade, sempre que houver no cardápio a introdução de alimento atípico ao hábito alimentar escolar, e o mesmo poderá ser ofertado de modo permanente desde que o índice 
de aceitabilidade não seja inferior a $85 \%$ (oitenta e cinco por cento).

$\mathrm{Na}$ figura 03, o gráfico que representa a aceitabilidade do mel de abelha na merenda escolar pelo GRUPO 2, reflete que 50\% dos alunos do grupo adoraram consumir o mel na alimentação escolar e 26,7\% gostaram, porém $10 \%$ da amostra foi indiferente a oferta do mel e $13,3 \%$ não gostaram do alimento no cardápio, isso demonstra um percentual de aceitabilidade de $76,7 \%$, ou seja, uma aceitabilidade inferior a mínima exigida pelo FNDE para se introduzir um alimento no cardápio da merenda escolar, assim pelo grupo 2, não seria possível a oferta de mel na escola em estudo.

Apesar da aceitabilidade do grupo 2 ter sido abaixo do proposto pelo FNDE é importante destacar que um grande entrave ao incremento do consumo do mel é o fato de o brasileiro, de forma geral, considerar esse alimento como apenas um medicamento natural útil para as vias respiratórias e que sem um bom desenvolvimento de ações educativas que mostrem que o mel é um alimento rico em nutrientes a aceitação do mesmo não será tão tolerante (EBELING, 2002).

Figura 04: Opinião dos alunos dos Grupos 1 e 2 sobre a forma como o mel foi ofertado (em sachê)

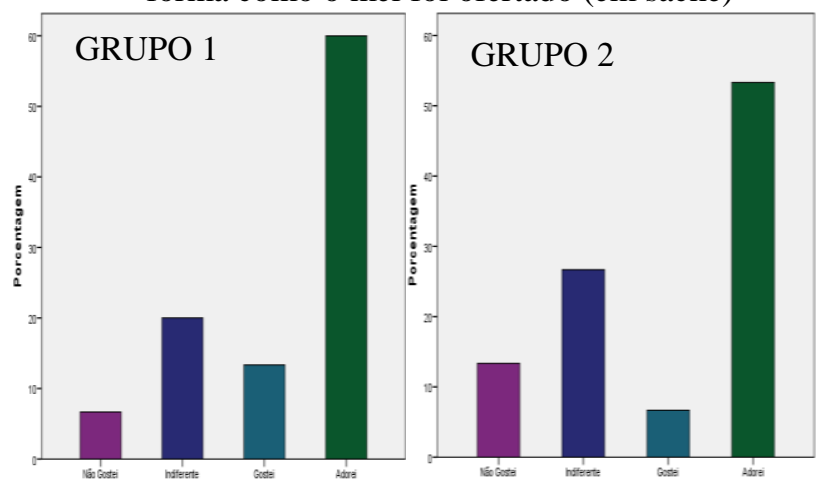

O parecer dos alunos relacionado a forma de receber o mel (em sachê) foi parecida quando comparado os dois grupos. No GRUPO 1, 60\% da amostra adorou o mel em sachê e 13,3\% gostaram dessa forma, $20 \%$ foram indiferentes ao sachê e 6,7\% não gostaram de receber o mel de abelha em sachê. No GRUPO 2, 53,3\% dos alunos adoraram o mel embalado em sachê e 6,7\% gostaram, enquanto que $26,7 \%$ foram indiferentes e $13,3 \%$ não gostaram.

Nota-se que de modo geral a forma em sachê agrada aos alunos, de acordo com Scherer (2006), uma ação importante realizada para a introdução de mel de abelha na merenda escolar é oferecê-lo em sachê com consumo diário estimado em $10 \mathrm{~g} /$ aluno/dia.

Tabela 05 Amostras dos alunos (grupos 1 e 2) que gostariam que o mel fosse oferecido mais vezes no cardápio da merenda escolar.

\begin{tabular}{lcrcc}
\hline Querem mel mais vezes & Grupo 1 & $\%$ & Grupo 2 & $\%$ \\
\hline Sim & 30 & 100 & 26 & 86,7 \\
Não & 0 & 0 & 4 & 13,3 \\
\hline Total & 30 & 100 & 30 & 100 \\
\hline
\end{tabular}

Examinando os dados da tabela 05 evidencia-se que a grande maioria dos alunos querem que o mel seja ofertado mais vezes no cardápio escolar, principalmente os do grupo 1 onde $100 \%$ da amostra demonstra que quer o mel com mais frequência na merenda escolar, 3,3\% dos alunos desse mesmo grupo afirmaram em outro questionamento não terem gostado do mel na merenda, porém demonstra-se consciência da importância do alimento ao responderem que mesmo não gostando desejam que o mel seja incluído mais vezes no cardápio escolar.

\section{CONCLUSÕES}

Com fundamento nos resultados alcançados, examinados e discutidos no presente estudo, constata-se que:

Os alunos da escola em estudo realmente nunca haviam recebido mel de abelha na merenda escolar e que o mel apresentou uma excelente aceitabilidade por parte dos alunos, sendo essa superior aos padrões mínimos exigidos pelo FNDE no grupo 1 e um pouco inferior no grupo 2 , demonstrando uma possível influência cultural nesse grupo.

A forma como o mel foi ofertado (em sachê) apresentou boa aceitabilidade nos dois grupos, porém o grupo 1 demonstrou uma melhor aceitação;

Dessa forma, constata-se que o mel de abelha é um alimento natural de grandes benefícios para os escolares e que apresenta excelente aceitabilidade entre esses quando ofertado em sachê, demonstrando-se assim que é viável a sua introdução como alimento na Merenda Escolar.

\section{REFERÊNCIAS BIBLIOGRÁFICAS}

ACCIOLY et. al. Nutrição em Pediatria e Obstetrícia. Guanabara Koogan, 2 ${ }^{a}$ Ed.Rio de Janeiro, 2012.

BARBETTA, P. A. Estatística aplicada às Ciências Sociais. 4 ed.Florianópolis: UFSC, 2001. 338p.

BRASIL. Instrução Normativa n. ${ }^{\circ}$ 11, de 20 de Outubro de 2000. Diário Oficial, 23 de outubro de 2000. Seção 1, p.16-17. Regulamento técnico de identidade e qualidade do mel.

\section{CPRM. Diagnóstico do Município de São Domingos de} Pombal. Projeto Cadastro de Fontes de Abastecimento por água subterrânea no estado da Paraíba. Recife, 2005. Disponível

em: http://www.cprm.gov.br/rehi/atlas/paraiba/relatorios/SA OD174.pdf. Acesso em 19 de agosto de 2013.

EBELING, E. Exploração apícola. In: Congresso brasileiro de apicultura, 14., 2002 Campo Grande, MS. Anais. Campo Grande:CBA: UFMS: FAAMS, 2002. p.166.

FNDE. Alimentação Escolar. Disponível em: http://www.fnde.gov.br/index.php/programasalimentacao-escolar. Acesso em 03 de janeiro de 2013

GIL, A. C. Como elaborar projetos de pesquisa. 4 ed. São Paulo: Editora Atlas S.A., 2002. cap. 4, p.41-56.

GÜNTHER, H. Pesquisa Qualitativa Versus Pesquisa Quantitativa: Esta É a Questão? Psicologia: Teoria e Pesquisa, Sciello, vol. $22 \mathrm{n}^{\circ} 2$, p.201-210 May/Aug. 2006.

MAGALHÃES et al.Viabilidade da introdução do mel na merenda escolar: oportunidade e desafio para o 
agronegócio apícola. Revista de economia agronegócio. Vol.7 n. 1. Florianópolis. UFSC, 2005.

SCHERER, W. Mel na merenda escolar. Porto Alegre, UFRGS, 9 jun. 2006. Palestra ministrada no Seminário de Agronegócios em Apicultura do PPG-Agronegócios do Cepan/UFRGS.

SILVA.R. A et al. Composição e Propriedades Terapêuticas do mel de abelha. Ver. Alim. Nutr. Araraquara, v.17, n.1, p.113-120, jan./mar. 2006.
PINHEIRO, et. al.. Tabela para avaliação de consumoalimentar em medidas caseiras. Rio de Janeiro: 2005.

PHILIPPI, S. T. Tabela de composição de alimentos: suporte para decisão nutricional. Brasília: UnB, 2001. $133 \mathrm{p}$

VITOLO, M.R. Nutrição da gestação ao envelhecimento. Ed Rubio. Rio de Janeiro, 2008. 